\title{
Communication Strategy, Central Banking and Credibility Bonus - A Study dealing with Impossible Trinity in Indian Context
}

Link to publication record in Manchester Research Explorer

Citation for published version (APA):

Yanamandra, S. (2012). Communication Strategy, Central Banking and Credibility Bonus - A Study dealing with Impossible Trinity in Indian Context. In host publication

\section{Published in:}

host publication

\section{Citing this paper}

Please note that where the full-text provided on Manchester Research Explorer is the Author Accepted Manuscript or Proof version this may differ from the final Published version. If citing, it is advised that you check and use the publisher's definitive version.

\section{General rights}

Copyright and moral rights for the publications made accessible in the Research Explorer are retained by the authors and/or other copyright owners and it is a condition of accessing publications that users recognise and abide by the legal requirements associated with these rights.

\section{Takedown policy}

If you believe that this document breaches copyright please refer to the University of Manchester's Takedown Procedures [http://man.ac.uk/04Y6Bo] or contact uml.scholarlycommunications@manchester.ac.uk providing relevant details, so we can investigate your claim.

\section{OPEN ACCESS}


Communication strategy, Central banking and Credibility bonus

- A study dealing with "Impossible Trinity" in the Indian context

Srinivas Yanamandra

April 2012

(Paper presented at the "International Conference on Economics and Finance", hosted by the Nepal Rastra Bank at Kathmandu on April 20-22, 2012) 
Electronic copy available at: http://ssrn.com/abstract=2047226 


\title{
Communication strategy, Central banking and Credibility bonus - A study dealing with "Impossible Trinity" in the Indian context
}

\author{
Srinivas Yanamandra \\ Assistant General Manager, Compliance Group, ICICI Bank, India \\ (srinivas.yanamandra@icicibank.com)
}

\begin{abstract}
The Communication strategy for central banks is traditionally interlinked with one of their important mandates - conduct of monetary policy. Credibility to central bank actions in the process is achieved by keeping the market expectations more closely synchronised with its own, through the art of communication. However, the management of "Impossible Trinity" in the context of Emerging Market Economies expands the scope of communication strategy of central banks to horizons other than the conduct of monetary policy. The paper, therefore, examines a pertinent research question - How did the management of "Impossible Trinity" impact the communication strategies adopted by Reserve Bank of India (RBI) and the credibility of its actions amongst the market participants? The paper reviews the RBl's efforts to demystify its policy stances since past few years under the policy options thrown up by the impossible trinity and its perceived impact on market participants. The Case study, drawn from existing academic literature, variety of $\mathrm{RBI}$ publications and speeches of $\mathrm{RBI}$ senior officials, review of media reports, can constitute an important contribution to the emerging research area in the South Asian central banking.
\end{abstract}

JEL classification: E58, E44, E52

Keywords: Central Bank Communication, Credibility Bonus, Monetary Policy Transparency, Exchange Rate Stability

Disclaimer: Views expressed in the paper are personal and do not necessarily represent the views of the organisation that the author represents. The author is grateful to the officials of Reserve of Bank of India (Ms. Alpana Killawala, Chief General Manager, Department of Communications; Dr. Rajiv Ranjan, Director, Department of Economic Policy and Research; and Mr. PSS Vidya Sagar, Assistant Adviser, Department of Economic Policy and Research) for their helpful comments on the initial draft of this paper. The author would like to acknowledge the support of his colleagues (Mr. Karan Ahluwalia and Ms. Surbhi Ogra) for their excellent research assistance. While data/references have been obtained from various sources, any omissions/errors are the responsibility of author alone. 


\section{Introduction}

Communication strategy for central banks is traditionally interlinked with one of their important mandates - conduct of monetary policy. Credibility bonus to central banking communication policies, generally, arises from the clear understanding of the market participants, not only of what the central bank policy action currently is, but of what it expected to be in the future. The available academic evidence suggests that communication can be an important and powerful part of the central bank's toolkit since it has the ability to move financial markets and to enhance the predictability of monetary policy decisions. However, large variation in communication strategies across central banks suggests that a consensus has yet to emerge on what constitutes an optimal communication strategy especially in the context of Emerging Market Economies (EMEs).

Against this backdrop, the impact of "Impossible Trinity" principle (which states that it is impossible for a central bank to have all three of the policy goals at the same time - a) a fixed exchange rate, b) free capital movement (absence of capital controls) and c) an independent monetary policy) on the timing and content of communication strategy of central banks is an interesting study in respect of which available academic literature does not offer much empirical evidence. Further, the recent phenomenon of EMEs embracing the "Impossible Trinity" in a modified form also had thrown up several challenges to the communication policies of central banks in these economies. At the basic level, they have reduced the policy options arising from "Impossible Trinity", to "dilemma" of choosing between monetary policy independence and exchange rate stability (largely facilitated by the adequacy of international reserves). The scope of communication strategy of central banks in these EMEs, therefore, expands to horizons other than the conduct of monetary policy.

Against the above two distinct but interdependent theoretical perspectives, the paper examines a pertinent research question - How did the management of "Impossible Trinity" impact the communication strategies adopted by Reserve Bank of India (RBI) and the credibility of its actions amongst the market participants? As an attempt to explore an answer to this research question, the paper examines the RBl's efforts to demystify its policy stances since past few years and its perceived impact on market participants. The Case study, drawn from existing academic literature, variety of $\mathrm{RBI}$ publications and speeches of $\mathrm{RBI}$ senior officials, review of media reports, can constitute an important contribution to the emerging research area in the South Asian central banking. 


\section{Literature Review}

\section{Mystique of a central banker}

Overtveldt (2010) observes that the current research on central bank communication, owes to central bankers like Alan Greenspan, and their Delphic utterances, for generating much learned commentary on why central bank communication is important. It has even been considered blasphemous to speak about central bank communication, in the speeches of the Governors of Reserve Bank of India (RBI) in the recent times, without first paying homage to Greenspan (Subbarao 2011, Reddy 2008). Greenspan was considered by many as the master of masters when it comes to the subject of central bank communication, as illustrated by his famous statement: "Since l've become a central banker, l've learned to mumble with great incoherence. If I seem unduly clear to you, you must have misunderstood what I said". Even more to the point is this statement, also from Greenspan: "I know you believe you understand what you think I said, but I am not sure you realise that what you heard is not what I meant" (Blinder et al 2009).

It is therefore not surprising that a few decades ago, as Blinder et al (2009) observes, conventional wisdom was that central bankers should say as little as possible, and say it cryptically. Central bankers used to work behind the spectacularly complex (or at least esoteric) language they use to communicate with the outside world. As Liaquat Ahamad says in his book, "Lords of Finance", central bankers had previously believed that in times of crisis, it is prudent to obey the admonition of mothers, across cultures, to their children: "If you can't say anything nice, don't say anything at all." This follows from the recurring dilemma that central bankers face in times of panic. If you make an honest public statement, you end up feeding the frenzy. On the other hand, if you try to be reassuring, you have to twist the truth.

Overtveldt, (2010) further observes that hard-to-interpret communications of central bankers like Greenspan, accordingly, bred a proliferation of analysts who, post the financial crisis, specialised in deciphering what central bankers really say when they speak. On the other hand, central bankers have been increasingly persuaded that even in times of stress, they are better off communicating rather than not communicating. Therefore, the central theme of the academic literature on central bank communication - almost all of it written in this decade - is that the central bank communication is not just a matter of openness and transparency, but also of education, guidance, persuasion and dialogue; and of listening and learning (Subbarao, 2011).

\section{Why do central banks communicate?}

Literature provides several reasons for importance of central bank communication while conducting monetary policy decisions - maintaining the independence and accountability, managing public expectations and enhancing the credibility of central banking actions.

Kydland and Prescott (1977), Nobel Prize wining economists, were the first to push central bank communication towards rules over discretion and greater transparency. Over the recent past, the understanding of central bank transparency and 
communication has changed dramatically also owing to the notion that independent central banks should be more accountable. Further, central banks are increasingly embracing more open communication in recent times to counter the criticism that an autonomous central bank comprising unelected decision makers was inconsistent with a democratic structure (Blinder et al, 2009).

Woodford (2005) states that "Central Banking is management of expectations" and that the central banks affect the economy as much through their influence on expectations as through any direct, mechanical effects of central bank trading in the market for overnight cash. As it became increasingly clear that managing expectations is a useful part of monetary policy, communication policy rose in stature from a nuisance to a key instrument in the central banker's toolkit. This has been beneficial, not only from the point of view of reducing the uncertainty with which traders and other economic decision-makers must contend, but also from that of enhancing the accuracy with which the central banks are able to achieve the effects on the economy that they desire, by keeping the expectations of market participants more closely synchronised with their own.

Generally, investors update their own views in response to the information conveyed by the central bank. Various studies, therefore, found that financial markets react to information on the outlook that central banks provide (e.g., Andersson, Dillén and Sellin, 2001). Kohn and Sack (2004) argue that private agents may attach special credence to the economic pronouncements of their central bank, especially if the bank has established its bona fides as an effective forecaster. The apparent reason is that central banks generally have, or may be believed to have, superior information on the economic outlook. Central banks usually devote many more resources than private sector forecasters to forecasting and even to estimating the underlying unobservable state of the economy. Markets, therefore, expect that credibility of central banks is established furthermore when central banks explain both their actions and the thinking that underlies those actions (Blinder et al, 2009).

\section{Does communication by central banks really matter?}

An early contribution in this regard is made by Guthrie and Wright (2000), who, without distinguishing among different types of communication, provide compelling evidence that communication by the Reserve Bank of New Zealand (RBNZ) has sizable and long-lasting effects on interest rates across the maturity spectrum. Kohn and Sack (2007) argued that the volatility of various asset prices reacts significantly to statements by the Federal Open Market Committee (FOMC) in US and its members. They argue that the increased volatility is evidence that central bank communication conveys relevant information to market participants. Ehrmann and Fratzscher (2004) assessed the communication strategies of the Federal Reserve, the Bank of England and the European Central Bank and their effectiveness. Based on the content, timing and consistency of statements by the policy committees and its individual members as well as the voting behaviour, they argued that the three central banks are following fundamentally different communication strategies. Their central finding is that the predictability of policy decisions and the responsiveness of financial markets are equally good for the Federal Reserve and the ECB, though there are important differences in the type of communication that financial markets react to. 
Moessner and Nelson (2008) evaluated the behaviour of financial markets in the United States, the euro area and New Zealand in light of the communication strategies of central banks, in order to assess whether the provision of policy rate guidance by central banks impairs market functioning. While they found evidence that central bank policy rate forecasts influence market prices in New Zealand, no evidence was found to state that such guidance or forecasts impair market functioning. The results have shown that the risk of impairing market functioning is not a strong argument against central banks' provision of policy rate guidance or forecasts. The findings therefore suggest that there may not be a single best approach to central bank communication, and that the most effective way of communication depends on the circumstances and the environment a central bank operates in (Woodford, 2005). Central banks are, therefore, increasingly becoming known for "creating news" (e.g., by moving short-term interest rates in a desired way) and for "reducing noise" (e.g., by increasing predictability of central bank actions and lowering market uncertainty) (Blinder et al, 2009).

\section{Critique of the academic literature}

A critique of the academic literature on central bank communication is often found in speeches of RBI Governors (Subbarao 2011, Reddy 2008). The context to my research work is, therefore, made from the brief review of the speeches.

Academic literature, so far, had the perception of central bank communication as synonymous with monetary policy pronouncements as they are at the heart of central banking. Further, much of the literature focused only on the structured communication by central banks as formal periodic statements are normally valued significantly in the context of monetary policy management. Research work is largely due in regard to the role of unstructured communication (such as ad hoc speeches and comments by central bank officials) even in the developed economies. Therefore, in the context of "impossible trinity" challenge faced by central banks, communication dynamics in the context of monetary policy alone can at best address the challenges of a central bank only partly.

The study of central bank communication is largely restricted to central banks of developed economies. Challenges for communication policy are, considerably, more complex for central banks in EMEs for various reasons. More generally the style and content of communication in EMEs has evolved over time consistent with progress in financial sophistication. Further, in a globalised world, communications by a central bank in advanced economies have a great impact on financial markets in EMEs. Other challenges in regard to effective communication strategies in EMEs arising from issues such as - dual role of central bank as monetary authority and banking supervisor - have not largely been subjected to research so far.

My paper, therefore, attempts to fill this gap in literature partly by studying the central banking communication strategy and the credibility of its action in the context of dealing with "impossible trinity" challenge in one of the largest EMEs i.e., India. 


\section{Conceptual Framework}

\section{Impossible trinity - An introduction}

The "Impossible Trinity" (also known as the Trilemma) is a fundamental contribution of the Mundell-Fleming framework to economics, which states that it is impossible for a central bank to have all three of the policy goals following at the same time - a) a fixed exchange rate, $b$ ) free capital movement (absence of capital controls) and c) an independent monetary policy. Aizenman (2010), therefore, argued that a key message of the "Impossible Trinity" is scarcity of policy instruments and illustrates the impossible trinity in the form of a triangular framework (see figure 1 below).

Figure 1: Framework of "The Impossible Trinity"

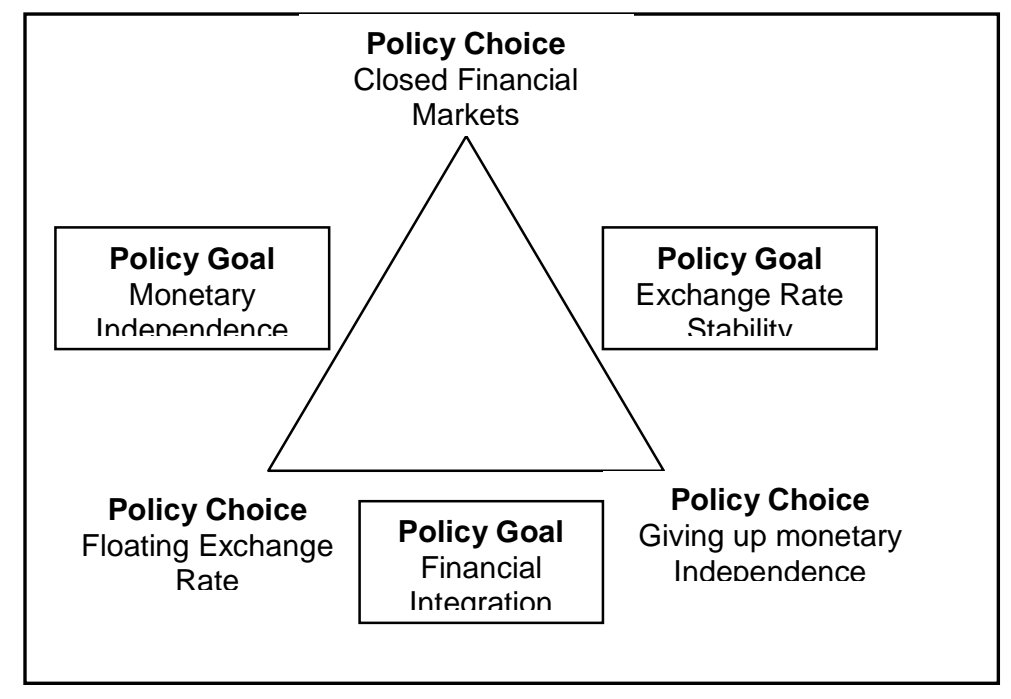

Source: Aizenman (2010)

Each of the three sides of the triangle, representing monetary independence, exchange rate stability, and financial integration, depicts a potentially desirable policy goal for a central bank. However, the "Impossible Trinity" principle holds that it is not possible to be on all three sides of the triangle simultaneously. The top vertex, labeled "closed financial markets," is associated with monetary policy autonomy and a fixed exchange rate regime. But it represents the preferred choice of most developing countries in the mid to late 1980s. The left vertex, labeled "floating exchange rate regime", is associated with monetary independence, and financial integration - the preferred choice of the U.S. during the last three decades. The right vertex, labeled "giving up monetary independence", is associated with exchange rate stability (a pegged exchange rate regime), and financial integration - the preferred choice of East-Asian countries during their pre-1997 years.

The sharp predictions of the Impossible Trinity principle and its crisp intuitive interpretation made it the Holy-Grail of the open economy neo-Keynesian paradigm. The impossible trinity has become self-evident for economists and for a long period of time this insight is shared by academic practitioners and central bankers alike. 


\section{Impossible trinity and the EMEs}

Notwithstanding its real life validation, it is not as if Mundell's 'Impossible Trinity' is inviolable as many of the assumptions underlying this model do not often hold. The new open economy macro-economy models that build in price rigidities and monopolistic competition demonstrate policy dynamics quite different from those built in the Mundell-Fleming tradition. As Dr. Duvvuri Subbarao, Governor of RBI states, "It is also not the case that countries are forced into corner solutions at the nodes of the impossible trinity triangle" and their asymmetric impact, it is widely argued in academic literature that many EMEs have opted for middle solutions.

Aizenman $(2008,2010)$, for instance, argued that a lingering challenge is that in practice, most countries rarely face the binary choices as articulated by the original "Impossible Trinity" principle. Instead, it was observed that countries chose the degree of financial integration and exchange rate flexibility. Even in rare cases of adoption of a strong version of a fixed exchange rate system (like the currency-board regime chosen by Argentina in the early 1990s), the credibility of the fixed exchange rate changes overtime, and the central bank rarely follows the strict version of currency-board. Similarly, countries choosing a flexible exchange rate regime, occasionally (some frequently) actively intervene in foreign currency markets, and end up implementing different versions of a managed float system. In this context, using the methodology of "Trilemma Indexes", calculated for over a period of time in different countries, Aizenman, along with Chinn and Ito (2008) found that EMEs are holding voluminous international reserves, which helped them to pursue both a higher level of exchange rate stability and a higher weighted average of the other two policy goals through active foreign exchange interventions. Obstfeld, Shambaugh and Taylor (2008) argued that reserve accumulation, as a key tool for managing domestic financial instability, is used by central banks to protect the domestic banking sector, and domestic credit markets more broadly, while limiting external currency depreciation.

The "dilemma" of choosing between Monetary Policy Independence and Exchangerate Stability (with elements of intervention and adequacy of international reserves), therefore, present the middle-ground policy option, in the context of "Impossible Trinity" in EMEs.

\section{India and Impossible trinity}

Officially, RBI, as a central bank, always targeted to achieve price stability, economic growth and financial stability (not necessarily in that order) and did not aim to resolve "Impossible Trinity". This was indeed the case as long as the capital account was closed, prior to 1990s, when RBI used to could conduct its monetary policy and exchange rate policy independently of each other. But since 1993, with the opening up of the economy, the "Impossible Trinity" had an indirect influence on the central bank actions, but the actions of RBI suggest that it had preferred the reduced version

\footnotetext{
${ }^{1}$ Remarks of Dr. Duvvuri Subbarao from: "Price Stability, Financial Stability and Sovereign Debt Sustainability Policy Challenges from the New Trilemma" - inaugural speech delivered at the Second International Research Conference of the Reserve Bank of India at Mumbai on February 1, 2012
} 
of "Impossible Trinity" by adopting the middle solutions of open but managed capital account and flexible exchange rate but with management of volatility.

Hutchison, Sengupta and Singh (2010) explored the question, as to where India stands today with respect to the impossible trinity and associated issues. Using quarterly data from 1996 to 2009, they constructed "Trilemma Indexes" for India, as per the methodology developed by Aizenman, Chinn and Ito (2008). Consistent with findings in other EMEs, it was observed that an increase in financial integration, especially after the mid 2000s, has changed the policy trade-offs faced by RBI. In this context, they argued that India was able to actively manage the exchange rate and limit exchange rate volatility relative to other EMEs, by building up international reserves and intervening actively in the foreign exchange market. This has helped $\mathrm{RBI}$ to some extent in regaining control over monetary policy even in the face of capital inflows. Similar findings are shared by Sen Gupta and Manjhi (2011) who also noted that India has resorted to the multiple instrument approach for managing "Impossible Trinity", encompassing - active management of capital flows, especially volatile and debt flows; a moderately flexible exchange rate regime with the RBI intervening at times to prevent excessive volatility; sterilisation of these interventions through multiple instruments like Market Stabilisation Scheme (MSS) bonds and Cash Reserve Ratio (CRR) variations; and building up of a stockpile of international reserves. They argued that this intermediate approach has suited India well as it has been able to maintain a healthy growth rate, targeted monetary and credit growth rates, moderate inflation rate through most of the period and a sustainable current account deficit. However, Kobayashi (2009) argued that the maintenance of current framework adopted by India will serve as a risk to its medium to long-term macroeconomic stability. With the premise that independent conduct of monetary policy is indispensable to medium to long-term macro-economic stability and the deregulation of capital flows is requisite for its long-term growth, they argue that it will be necessary for India to review its foreign exchange policy and gradually increase the flexibility of exchange rate.

\section{Communication, Credibility bonus and impossible trinity}

Mohan and Kapur (2009) observed that the middle-ground solution, as outlined above, in response to "Impossible Trinity", through the multi-instrument approach, was enabled by the fact that both monetary policy and regulation of banks and other financial institutions and key financial markets are under the jurisdiction of the RBI, which permitted smooth use of various policy instruments flexibly at its discretion. Given further the multiplicity of instruments for managing the exchange rate volatility alongside the monetary policy implementation, in the context of RBI, it would be, therefore, interesting to understand how RBI handles its Communication Strategy for achieving credibility to its actions. The paper attempts to explore an answer to this research question through a study of recent events in India.

It is, however, admitted upfront that communication policy is only one of the variables influencing the credibility of policy actions of central banks as economic data get influenced by macro-economic variables such as capital flows, liquidity in market, economic growth conditions, and business expectations. However, it is equally appropriate to state that, being an important variable in the whole gamut of central banking activities, communication strategy warrants a separate study as has been attempted in this paper. 


\section{RBI - Communication strategy and Credibility bonus}

\section{Communication strategy of RBI}

Faced with - multiple tasks, a complex mandate, and availability of various instruments at its disposal - clear and structured communication is considered by $\mathrm{RBI}$ as critical for its effective functioning. The goal of RBI communication strategy has thus been to promote credibility and understanding of monetary policy, and enabling participants to map the changing economic circumstances into anticipation of the broad policy direction with reasonable accuracy. The guiding principles of the Reserve Bank's communication policy in the context of its overall strategy are transparency, comprehensiveness, relevance and timeliness with a view to improving public understanding as a systematic process of continuous efforts as under:

- Transparency - through explanation of policy stance with rationale, information and analysis;

- Comprehensiveness - through coherence, clarity and credibility in articulation through formal structured and periodic statements, statutory/non-statutory publications, speeches and committee reports as well as through reporting/ dissemination of information;

- Relevance - through ensuring that the communication is sensitive to the target audience; different types of communication instruments are therefore used by $\mathrm{RBI}$ to suit the relevant audience;

- Timeliness - through dissemination of information through the official website (www.rbi.org.in) on real time basis; it is enhanced through pre-announced periodicity of standard communication instruments; advance release calendars and review cycles;

In this context, $\mathrm{RBI}$ also recognises the complexity inherent in the Indian economy at this stage of its development. It therefore explicitly states in its Communication Policy that "while policy and market preferences generally converge and communication is intended to improve the predictability of policy decisions, an element of surprise can often enhance the effectiveness of policy actions when the preferences are in opposing directions, albeit with concurrent or ex post communication of the rationale thereof'.2. The Communication policy is therefore designed to be operated as principle-based rather than rule-based instrument. The overall approach to communication is driven by the principle of democratic accountability, enhancing the effectiveness of monetary policy by creating news and/or reducing noise.

\section{Monetary Policy independence}

In the Indian context, pursuant to the preamble to the Reserve Bank of India Act, 1934 the objectives of monetary policy relate to maintaining of price stability and

\footnotetext{
${ }^{2}$ Extracted from the Communication Policy of RBI available at www.rbi.org.in
} 
ensuring adequate flow of credit to the productive sectors of the economy, thereby endeavoring to maintain a judicious balance between economic growth and price stability. To achieve these objectives, the monetary policy framework and the associated operating procedure of monetary policy in India have also evolved over time. The monetary policy operating procedure initially underwent a significant change in 1999 following the introduction of Interim Liquidity Adjustment Facility (ILAF), under which liquidity injection was done at the Bank Rate and liquidity absorption was through fixed reverse repo rate. The ILAF gradually transited into a full-fledged liquidity adjustment facility (LAF) and operated, from November 2004, through overnight fixed rate repo (central bank liquidity injection rate) and reverse repo (central bank liquidity absorption rate) to provide necessary guidance to market interest rate. Thereafter, overnight management of systemic liquidity at desired interest rate emerged as the most active instrument of monetary policy. Finally, in May 2011, a revised monetary policy operating procedure was announced by RBI, which currently constitutes the guiding framework for conduct of monetary policy.

\section{a) Communication Strategy in the context of monetary policy}

The process of monetary policy formulation in India had traditionally been largely internal with only the end-product of actions being made public. However, the process has, over time, evolved into a more communication-oriented exercise as under:

- Governor as the ultimate authority in monetary policy matters: $A t \mathrm{RBI}$, it is the Governor, who is the ultimate authority to take decisions on monetary policy matters. However, in keeping with international best practice, the RBI has constituted several committees (standing and ad hoc) and groups which play a critical role with regard to policy advice. The whole range of consultations and technical analysis through these committees/groups enable the Governor to make the best possible decision under the circumstances besides enhancing the transparency of the policymaking process.

It is apt to mention here the "cacophony problem," pointed out by Blinder (2004) in the context of monetary policy decisions subsequently explained by a committee rather than by a single individual. This refers to the danger that too many disparate voices might confuse rather than enlighten the public-especially if the messages appear to conflict. RBI addresses this danger, by placing in public domain w.e.f. January 2011, the main points of discussion of the Technical Advisory Committee (key Committee with outside experts involved in giving Policy advice to RBI) in public domain only with a lag of roughly four weeks after the meeting of the Committee. The attempt also has one been to promote transparency though there is no legal compulsion in India to reveal content of such discussions in public domain unlike in the United States.

- Consultative and participative communication with an external orientation: While monetary policy formulation is a technical process, it has evolved to be a highly consultative and participative process. This not only enhances the transparency of monetary policy but policy decisions become informed with the analysis and viewpoints of the concerned stakeholders. As many outcomes in modern market-based economies are guided by expectations, a consultative process also helps in managing expectations. 
Internally, within the RBI, the work process has been re-oriented to focus on technical analysis, co-ordination, horizontal management and more market orientation. Internally, Monetary Policy Department (MPD), Department of Economic and Policy Research (DEPR) and Department of Statistics and Information Management (DSIM) provide independent technical inputs and assessment in the monetary policy strategy meeting chaired by the Governor and attended by the top management.

Externally, since banks are the major counterpart of the RBI, pre-policy consultations through resource management discussions are held with 20 large commercial banks which together account for more than three-fourths of banking business. In addition, in the financial sector, consultations are held with the Indian Banks Association (IBA), urban and rural co-operative bank/credit associations and association of non-banking financial companies. In the real sector, consultations are held with national level trade associations. Consultations are also held with select economists and senior economic journalists to ascertain their reading of the economic situation and policy recommendation.

Thus the process leading to monetary policy actions entails a wide range of inputs involving the internal staff, various internal committees, market participants, academics, and financial market experts.

- New operating framework: W.e.f., May 2011, RBI had adopted a new operating framework for conduct of monetary policy to improve implementation and transmission of monetary policy. Under the new framework a) the weighted average overnight call money rate was explicitly recognised as the operating target of monetary policy b) the repo rate was made the only one independently varying policy rate c) a new Marginal Standing Facility (MSF) was instituted under which scheduled commercial banks (SCBs) could borrow overnight at their discretion up to one per cent of their respective Net Demand and Time Liabilities (NDTL) at 100 basis points above the repo rate $\mathrm{d}$ ), the revised policy rate corridor was defined with a fixed width of 200 basis points. The repo rate was placed in the middle of the corridor, with the reverse repo rate 100 basis points below it and the MSF rate 100 basis points above it.

The new operating framework is expected to improve the implementation and transmission of monetary policy from communication standpoint in several ways: a) explicit announcement of an operating target makes it clear to the market participants about the desired policy impact b) a single policy rate removes the confusion arising out of policy rate alternating between the repo and the reverse repo rates and improves the accuracy of signaling the monetary policy stance.

- Structured communication: The dissemination of monetary policy has been undertaken in a structured manner by RBI with the Annual Policy Statement and its mid-term Review announced in a meeting with the bankers where the Governor explains the rationale behind the measures at length. The announcement, in recent times, also includes the macro and monetary projections, together with the mention of the upside and downside risks. In order to further reduce the gap between the policy announcement and availability of 
rationale in public domain, $\mathrm{RBI}$ has recently started live telecast of this statement. The video recording is also made available on website in a couple of hours and retained for about a month thereafter.

The Monetary Policy announcement meetings are not one-way traffic; bankers are encouraged to give their feedback as also any other suggestions. After the policy announcement, the Governor addresses the press which includes the regional press through video conferences. The video recording of the press conference is kept on the RBI website for at least a month. The Governor and the Deputy Governor in-charge of monetary policy give interviews to print and electronic media over the next few days. RBI has also been interacting with researchers and analysts on the day after the policy announcement. The edited transcripts of all these interactions are also hosted on the website of RBI alongside the policy statements.

- Signaling of intentions: Received wisdom today is that successful monetary policy is not just a matter of effective calibration of overnight interest rates, but also of shaping market expectations of the way in which interest rates are likely to evolve going forward. Among the important instruments used by central banks for this purpose is the 'forward guidance' they provide in their monetary policy statements. The practice of providing forward guidance varies across central banks of developed economies. Starting early 2010, in keeping with the best practice, $\mathrm{RBI}$ too has begun providing forward guidance. While providing the 'forward guidance', RBI exercises utmost care and discretion in wording the conditionality surrounding the guidance. It ensures that the conditionality is not so vague as to lose all content value or is not so precise that the central bank becomes a prisoner of its words and loses any flexibility to deviate from the guidance should the underlying circumstances change. It has even communicated to market participants, through various interviews and speeches, the need to appreciate the conditionality and not interpret the guidance as an irrevocable commitment (refer Annexure for extracts of guidance given by RBI during announcements of monetary policy for FY 2011-12).

Thus, the conduct of monetary policy at RBI has evolved over a period of time into a communication management exercise in a structured manner and keeping in line with the international best practices.

\section{b) Credibility bonus in the context of monetary policy}

In the context of monetary policy, volatile interest rates generally obscure policy signals, while more orderly market conditions promote a rapid and predictable transmission of monetary policy impulses. Woodford (2005) argued that the predictable character of the central bank's decisions, do determine the (endogenous) expectations of the private sector at earlier dates, under the hypothesis of rational expectations. Market participants benefit from stable rates through stabilisation of expectations, which, in turn, promote the development of a term structure in the money market. Less volatile interest rates may also help financial institutions to better assess and manage their market risks. Insofar as the significance of current developments for future policy are clear to the private sector, markets can attribute a credibility bonus to the central bank's actions, and to a large extent, do the central banks work themselves. 
What has been the experience of RBI in regard to this theoretical principle? As the new operating procedure was implemented just less than a year ago, it may be too early to draw conclusions regarding its efficacy. However, I present herewith two broad parameters (relating to the movement of the overnight interest rate and the 10-year G-Sec rate) in order to assess the predictability of central bank actions amongst the market participants.

- Movement of overnight interest rate: In line with the practices internationally in other EMEs, RBl's new operating framework, announced in May 2011, stated that the weighted average overnight call money rate will be the operating target of the RBI. The operating objective of the monetary policy is to contain this rate around the repo rate within the corridor. The Marginal Standing Facility (MSF) rate constituted the ceiling of the formal corridor. At this rate (which is 100 bps above the policy rate), market participants have the freedom to draw funds from $\mathrm{RBI}$ against eligible collateral at their discretion. This facility is generally used when overnight rates have the tendency to increase significantly above the policy rate. On the other hand, the reverse repo rate (which is 100 bps below the policy rate) offers market participants an opportunity to deposit their residual surplus that they could not deploy in the market even at a rate significantly lower than the Policy Rate. This fixed interest rate corridor set by RBI for its conduct of monetary policy, can be stated to be reducing uncertainty and avoiding communication difficulties associated with a variable corridor, if the overnight average call money rate move close to the repo rate over a period of time.

Against this theoretical backdrop, the experience of $\mathrm{RBI}$ is depicted in the following chart.

Chart 1: Movement of Call rate (July 2010 - November 2011)

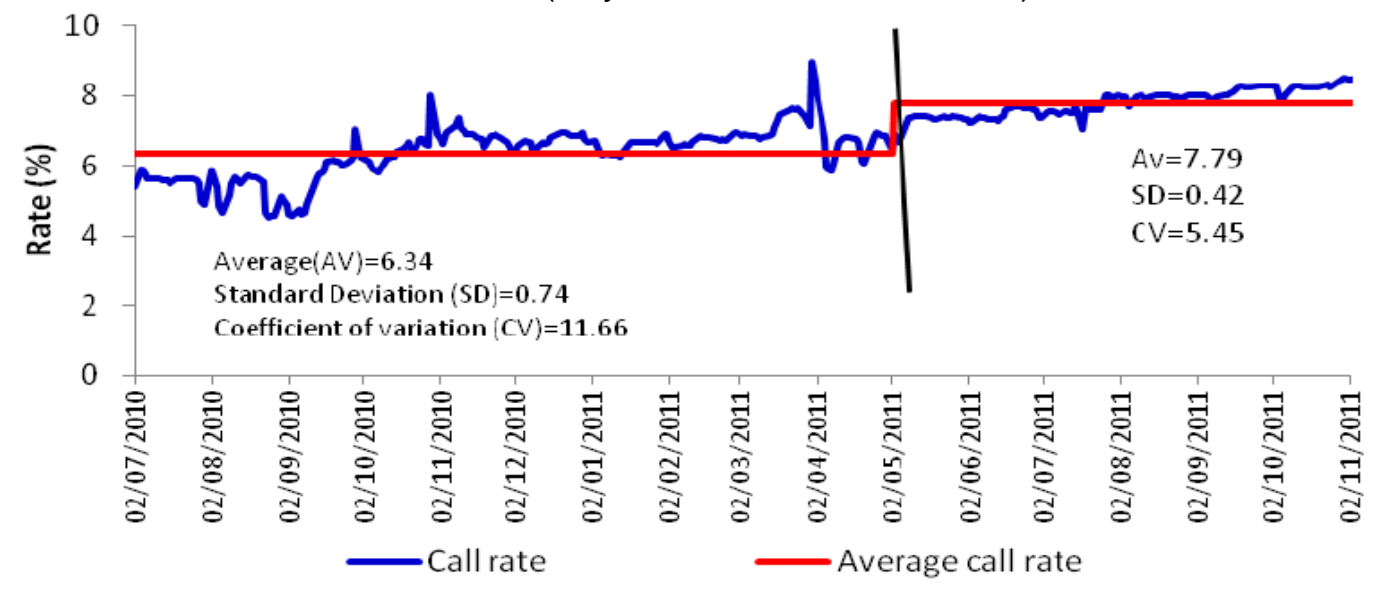

Source: Mohanty (2011)

As can be observed from the chart, overnight interest rate was found to be more stable since the implementation of new operating framework by RBI. This reflects the fact that the $\mathrm{RBI}$ is able to calibrate its liquidity management through its regular and fine-tuning operations (including managing market expectations 
through effective communication) in such a manner that overnight rates are generally aligned around its policy rate.

- Movement on $\mathbf{1 0}$ year G-Sec yield: Behavior of term structure against the monetary policy action is a subject of academic interest. Available academic evidence in the context of USA in this regard (see, Cook et al (1989), Kuttner (2001) and Faust et al (2002)), therefore, suggest that the monetary policy actions have the ability to influence the expectation of the future short-term rates for next couple of years. In the Indian context, Rituparna Das (2010) observed strongest sensitivity of the short end of the term structure towards expected monetary policy shocks.

The interest rate, for a longer horizon, however is normally influenced by factors other than the policy actions. For example, the 10-year rate, defined as the weighted average of the current one year rate and nine one-year forward rates depend partly on term premium, which is the additional compensation that investors require for risk of holding long-term instruments. The term premium in turn depends on the extent of real interest rate risk and the inflation risk, which in turn factors in the market expectations of the future state of the economy.

It can therefore be premised that, to the extent that the 10-year yield curve behave in a predicted pattern over a period of time, credibility bonus can be attributed to the central bank communication in managing the market expectations about long-term rates. This premise has therefore been tested against the data of the daily series of 10 year G-Sec yield from July 20, 2010 to February 9, 2012 (i.e., 10 months pre and post the announcement of new operating framework on May 3, 2011 by RBI) by computing the one day movement in basis points (bps) on a rolling basis for the entire data series. The movement of the yield curve, for the next day, was predicted using the 90th percentile movement based on data for last 252 trading days (both tails considered). The results are depicted in the chart reproduced below:

Chart 2: Movement of 10 year g-sec yield curve

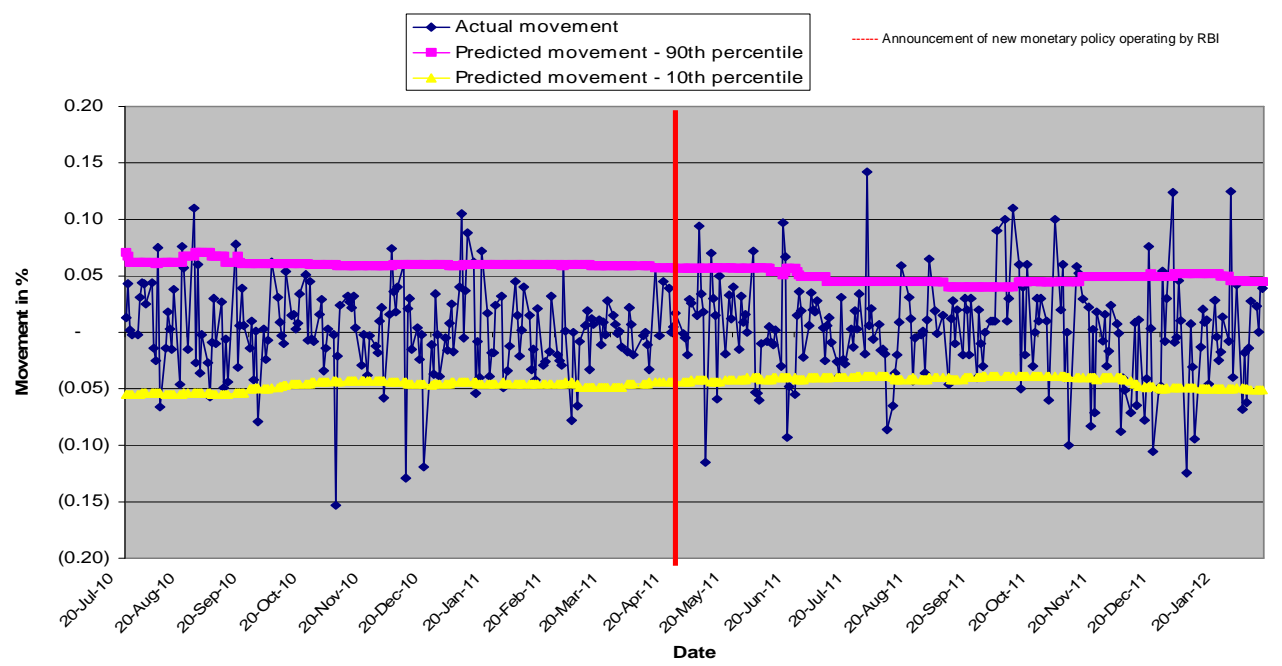

Source: Bloomberg 
Interestingly, the findings depicted above, are in contrast to the impact of the new operating framework on the overnight interest rate movement. The impact had been analysed in terms of a) number of outliers and b) extent of their standard deviation, pre and post the announcement of the new framework. Firstly, the days when the movement in the yield is higher than the 90th or 10th percentile, are considered as outliers. As can be observed from the above chart, the number of outliers, in the data pattern before the announcement of new operating framework, was found to be substantially lower than the number of outliers, post the announcement. Similarly, the standard deviation of outliers is also found to be higher, indicating a higher volatility, in the post-period (4.52 as against 3.73 for period prior to announcement of new framework).

These findings are however consistent with the empirical studies earlier mentioned in the beginning of this section, which stated that monetary policy actions have relatively higher ability to influence the short-term interest rates than the long-term interest rates. RBI experience in this regard, consistent with these studies, also indicate that the communication initiatives, as a strategic tool, have a limited causal relationship with long-term interest rates, as larger macroeconomic fundamentals may take lead than the communication initiatives in influencing the market expectations about the behavior of long-term rates.

\section{Exchange Rate stability}

India has been operating on a managed floating exchange rate regime from March 1993, marking the start of an era of a market determined exchange rate regime of the rupee. The exchange rate policy, therefore, has evolved over time in line with the gradual opening up of the economy as part of the broader strategy of macroeconomic reforms and liberalisation since then. As mentioned earlier, the exchange rate policy nuances are reflective of the dynamics of the middle ground solution (of intervention and maintenance of adequate international reserves) adopted by RBI. In this section, the broad contours of the exchange rate policy in India, from communication perspective, and their impact on managing market expectations amidst the high volatility of exchange rate in recent times, have been examined.

\section{a) Communication strategy}

RBl's stated policy with respect to exchange rate management is that it is not guided by a fixed or pre-announced target or band. However, RBI retained the flexibility to intervene in the market to manage excessive volatility and disruptions to macroeconomic stability and for taking relevant monetary and administrative measures. The structured communication messages through monetary policy announcements, supplemented with the speeches/press releases, information as per the Special Data Dissemination Standards (SDDS) requirements of the International Monetary Fund (IMF), and the publication of self-assessment reports on adequacy of forex reserves as per various monetary/trade-based indicators constitute the critical inputs to the market participants for predicting the RBl's stance on exchange rate volatility in the country. Each of these communication tools have been explained further as under: 
- Structured communication: The broad principles that have guided India's exchange rate management have been periodically articulated in the various Monetary Policy Statements. These are supplemented with communications through speeches and press releases. In addition to above sources of communication, $\mathrm{RBI}$ has been publishing regular reports and posting relevant information and statistics relating to foreign exchange market in line with the SDDS of the IMF to which India is a subscriber along with 67 other countries. As per the requirements of SDDS, the information is being made available at regular intervals in public domain by $\mathrm{RBI}$ along with advance dissemination of release calendars for these data categories. Usage of SDDS enhances the availability of timely and comprehensive statistics and contributes to the pursuit of sound macroeconomic policies and improved functioning of financial markets.

- Information on capital flows, intervention and forex reserves: As a result of calibrated and gradual capital account openness, the financial markets, particularly forex market, in India have also become increasingly integrated with the global network since 2003-04. This is reflected in the extent and magnitude of capital that has flown to India in recent years, which resulted in considerable volatility in exchange rates. RBl's intervention to curb the volatility is through purchases and sales of the US Dollars in the forex market and sterilising its impact on domestic monetary base through open market operations. Sales in the foreign exchange market are generally guided by excess demand conditions that may arise due to several factors. Similarly, the RBI purchases dollars from the market when there is an excess supply pressure in market due to capital inflows (Ranjan and Dua, 2010).

Empirical evidence in the Indian case has generally suggested that in the present day managed float regime of India, intervention has served as a potent instrument in containing the magnitude of exchange rate volatility of the rupee and the intervention operations do not influence as much the level of rupee (Pattanaik and Sahoo, 2001; Kohli, 2000). Adequacy of reserves has therefore emerged as an important parameter in gauging the ability of RBI to timely intervene in the market and to absorb external shocks. In this context, RBl's periodic communication to market participants is through the half-yearly reports on management of foreign exchange reserves for bringing about more transparency and enhancing the level of disclosure. These reports are prepared half yearly with reference to the position as of March 31 and September 30 each year with a time lag of about three months. The report contains information regarding the movement of reserves and information on the external liabilities vis-à-vis the foreign exchange reserves, prepayment/ repayment of external debt, Financial Transaction Plan (FTP) of the IMF, adequacy of reserves, etc. during the half-year under review. Objectives of reserves management, statutory provisions, risk management practices, information on transparency and disclosure practices followed by the $\mathrm{RBI}$ with regard to the reserves management are also covered in these half-yearly reports.

The other important aspect in this context, viz., the adequacy of reserves is earlier assessed through the import cover expressed in number of months. However the measures have been subsequently broadened to include the size, composition and risk profiles of various types of capital flows as well as the types of external shocks to which the economy is vulnerable. Over a period of time, 
adequacy is also assessed additionally through other measures relating to the extent of scheduled amortization of foreign currency debts (assuming no rollovers) during the following year. $\mathrm{RBI}$ publishes the current position of the forex reserves against these stated measures in the half yearly reports.

\section{b) Credibility bonus in the context of exchange rate policy}

Against the stated policy as mentioned above, for managing the exchange rate volatility, study of RBI communication pattern (during November 2011-January 2012) reveals certain interesting insights. During this period, the Indian Rupee (INR) has depreciated significantly against the United States Dollar (USD) much against the expectations of many market participants. The rupee has depreciated by nearly 20 percent against USD from April 2011 to December 2011. In terms of 6 and 36-currency trade-weighted Real Effective Exchange Rate (REER), during April to December, 2011 INR has depreciated against USD by 11.87 percent and 12.52 percent respectively. To put this into context, it can simply be stated that, during Lehman crisis period (April to December 2008), these two indices had depreciated by 11.11 percent and 10.54 percent respectively (RBI, 2011).

Considering the significant depreciation in the exchange rate, the RBl's communication with market participants has been in various forms as under:

- Structured communication: The monetary policy announcements of RBI for the first two quarters (covering the policy announcement for FY2012 and the first quarter review) did not contain any information relating to the exchange rate policy of $\mathrm{RBI}$ except stating that the INR-Dollar exchange rate showed two-way movements. The reason is largely due to the fact that REER (both 6 and 36 currency) has not shown any significant depreciation during the first quarter of the FY2012. It is when the REER started to show depreciation (of 6.3 percent, 2.0 percent and 4.1 percent for 6,30 and 36 REER), for the first time in FY2012, $\mathrm{RBI}$ subtly reiterated its stated policy on Exchange rate volatility in the second quarter review of monetary policy announced on October 25, 2011. Through this announcement, $\mathrm{RBI}$ indicated that its Exchange Policy is not guided by a fixed or pre-announced target or band. It further stated that the policy has been to retain the flexibility to intervene in the market to manage excessive volatility and disruptions to macroeconomic stability. The foreign exchange market, however, remained under pressure in the third quarter of FY2012, reflecting adverse global sentiments and moderation in capital inflows. Between end-March 2011 and January 13, 2012, the 6,30 and 36 REER depreciated by about 9 per cent each, primarily reflecting the nominal depreciation of rupee against the US dollar by about 13.2 per cent. Acknowledging that much of the depreciation happened during August-December, RBI had indicated in its third quarter review of monetary policy (announced on January 24, 2012) that it had taken a number of steps to stimulate capital inflows and curb speculation, besides also intervening in the market consistent with its policy of containing volatility and preventing disruptive movements. RBI had even gone up to the extent to explicitly state that it continues to closely monitor developments in the external sector and their impact on the exchange rate and will take action, as appropriate.

The dynamics of communication in the monetary policy announcements in regard to foreign exchange rates, as seen above, underwent changes consistent with 
the market movements FY2012. However, while the monetary policy announcements reflect the factual position, two critical aspects that arise from the review of these statements indeed convey the insights of $\mathrm{RBI}$ - that while its stated stance is maintaining non-interventionist approach in forex market, it also wanted to ease the nerves of market participants by informing them that it retains the flexibility to intervene at an appropriate time.

- Unstructured communication: The apparent ambiguity in the RBl's structured communication exercise stems from the fact that market participants were not certain as to what constituted an "appropriate time" for intervention by RBI. This led to mixed reactions from market, with one section of market predicting that $\mathrm{RBI}$ will be largely non-interventionist and there can be further fall in INR, the other section expected an action by RBI in December 2011 itself when the levels of INR reached similar to the volatility levels in 2008. RBI has therefore supplemented its structured communication with speeches/ interviews and media interactions for further conveying its rationale on the stated policy stance.

Initially during September 2011, the message to market was sent by the RBI Deputy Governor Dr. Subir Gokarn, who stated that "...[RBI] do not see any intervention from a rate targeting view point and that is something that would reflect a change in policy stance, which we are not doing at this point. If we do intervene at all, it would be with a very narrow perspective or narrow objective of smoothing of what might be a very volatile market situation, but nothing beyond that' $^{\text {'3 }}$. Similarly, Dr. Duvvuri Subbarao, Governor of RBI, also engaged with media and other market participants by stating that the exchange rate is largely being driven by global dynamics (during October-November 2011 largely due to crisis in the Euro Zone) and by assuring them that RBI expects "the reverse adjustment will take place when the European situation resolves itself". However, he was skeptical in his comments that he can not state "whether RBI is intervening or not but [it is] watching the market".4.

$\mathrm{RBI}$ clarified its rationale for the above statements in another media interview which Dr. Subir Gokarn had in November 2011, where he explained that the approach of $\mathrm{RBI}$ in regard to exchange rate movement is basically founded on the principle that INR is a market determined exchange rate within certain boundaries. While there was a sharp depreciation in 2008 when the rupee depreciated below 52, it rebounded sharply and then stabilised in the mid-40s for some period of time thereafter. The pattern has again shown up during the end of 2011 , largely driven by global considerations resulting in reversal of capital flows. $\mathrm{He}$ explained further that the foreign exchange reserves of India are not an outcome of persistent current account surpluses, unlike in many countries, particularly in the Asian region and are merely the result of excess of capital inflows over the current account deficit and to that extent reflect a cushion that India has against its external liabilities. He infact indicated that the markets should generally accept that INR is a floating currency and that there are measures in place or instruments in place to help hedge against that and forex exposures have to be hedged as much as possible. According to him, therefore,

\footnotetext{
3 "RBI to intervene foreign exchange market only to smoothen volatility", September 23, 2011: News article accessed online on March 30, 2012 at <www.indianexpress.com>

${ }^{4}$ "RBI reserves firepower for the worst", November, 24, 2011: News article accessed online on March 30, 2012 at $<$ articles.timesofindia.indiatimes.com>
} 
forex market interventions by $\mathrm{RBI}$ are "a sort of a smoothing activity, not a rate defending or a rate targeting activity ${ }^{35}$. Further, for the first time, RBI recorded a statement by Dr. Gokarn and placed it on its website to clarify its stance on the subject.

- Regulatory measures: While RBI confined to monetary policy announcement of non-interventionist stance during October 2011, engaged with market participants to clarify its rationale for the same in November 2011, it has stepped into further action during December 2011, with a host of regulatory measures aimed at ensuring stability of exchange rate. These included:

- Measures aimed at risk management in banks - reducing the Net Overnight Open Position of authorised dealers in foreign exchange;

- Measures to curb the speculation activities involving foreign currency restricting the rebooking of forward contracts by residents once they are cancelled, reducing limits of availing forex based on past performance considerations (from 75 percent to 25 percent), stipulating that the forward contracts under past performance basis are undertaken only on fully deliverable basis;

- Measures for increasing foreign capital inflows - deregulation of interest rates on NRE deposits and NRO accounts, permission to qualified foreign investors to invest in Indian equities, enhancing the all-in-cost ceiling stipulated earlier by $\mathrm{RBI}$ for external commercial borrowings (ECB)/Export Credit in Foreign Currency (ECFC) by resident firms, extension of time limit for repatriation of export proceeds by exporters etc.

The measures have resulted in arresting the falling rupee which regained more than 7 percent in January 2012 after witnessing 20 percent fall in 2011 . The reduction of INR intra-day volatility can be depicted in the chart below:

Chart 3: Movement of INR Intra-day volatility

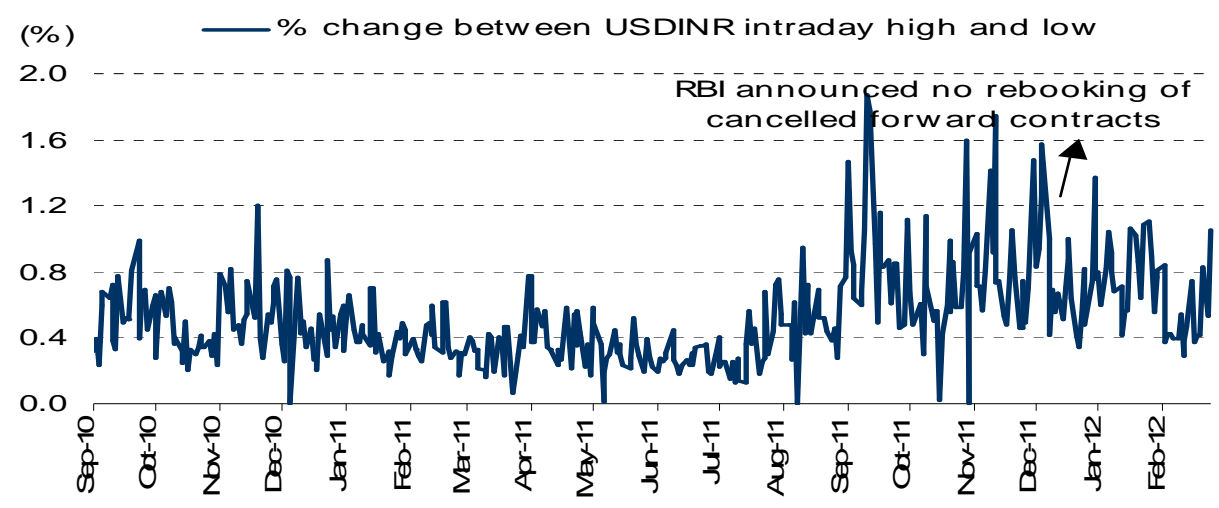

Source: RBI Bulletin

\footnotetext{
5 "RBI will intervene, but only to check Re volatility: Gokarn" November 17, 2011: Media Interview accessed online on March 30, 2012 at <www.moneycontrol.com>
} 
As can be seen from the chart, the volatility showed a marked decline after the announcement of measures by $\mathrm{RBI}$ for curbing the speculative activity in the market. After announcing these measures in mid December 2011, Dr. Subir Gokarn was candid in his comments when he stated that "the measures we have already unveiled are not the only ones we have. There are a number of other measures we can undertake to bring stability to the money market, and when the need arises we will use them" ${ }^{\prime \prime}$.

- Intervention by RBI: Despite all communication exercises by RBI on clarifying its non-intervention stance and leaving exchange rates to be market determined, $\mathrm{RBI}$ finally retained its credibility by demonstrating its commitment to the stated policy stance when it announced the data on sale and purchase of dollars by RBI in the market during November-December 2011. The data converted into a chart depicts as under:

Chart 4: Intervention by RBI (sale and purchase of dollars)

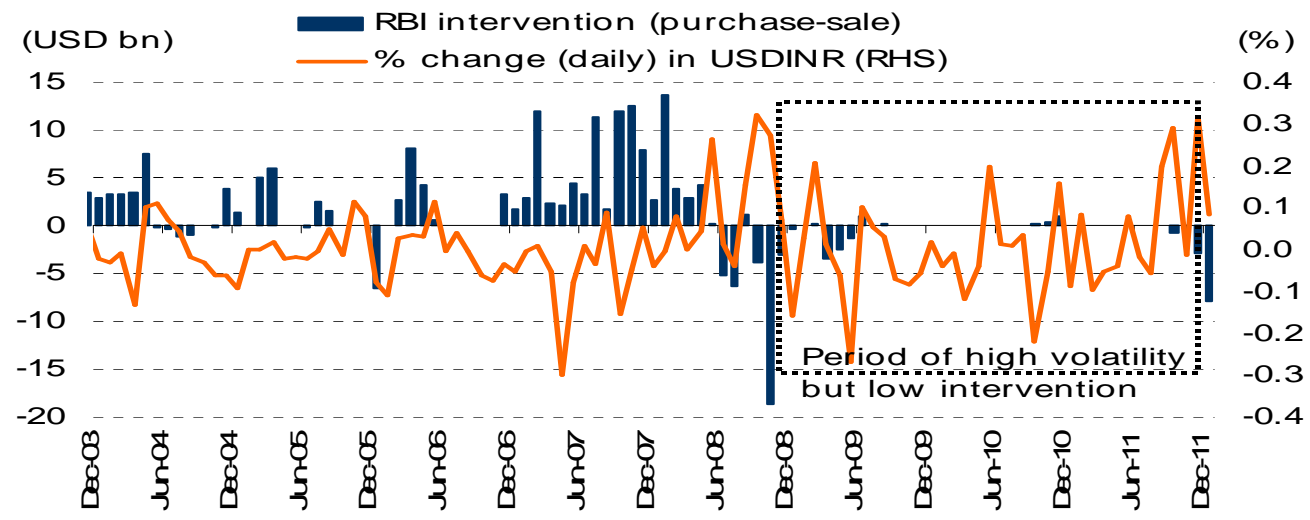

Source: RBI Bulletin

As can be seen, after a powerful depreciation in end- 2011, INR started 2012 on a strong note, gaining close to 7 percent in January against the USD. While this can be attributed to the surge in portfolio inflows in December 2011, increase in global liquidity provision by the European Central Bank (ECB) in late 2011, the intervention of $\mathrm{RBI}$ coupled with its other measures definitely can be credited in arresting the otherwise free fall of the rupee during the same period. This episode demonstrated that RBI, true to its policy stance and explanation of its rationale to market participants, intervened only to smoothen the volatility during the period of October-December 2011 after a three year non-intervention period.

\footnotetext{
6 "Subir Gokarn says "Rupee relatively stable" due to steps taken" December 20, 2011: News article accessed online on March 30, 2012 at <articles.economictimes.indiatimes.com>
} 


\section{Analysis and policy implications}

Over a period of time, the "dilemma" of choosing between effective conduct of Monetary Policy and exchange rate stability (with elements of holding of international reserves and intervention strategies) enabled a middle-ground approach to address the "Impossible Trinity" principle in the context of EMEs, like India. Speaking on this aspect of Impossible Trinity, RBI Governor Dr. Duvvuri Subbarao mentions, "to the extent you have a freely floating exchange rate you have greater, more independent monetary policy" . However, the implication of this middle-ground solution on the central bank communication, as observed from the experience of $\mathrm{RBI}$ in 2011 can be summarised as under:

\section{Communication initiatives, have a limited impact on influencing market expectations about behavior of long term interest rates}

Consistent with the previous empirical findings in the academic studies, from a monetary policy standpoint, a review of the impact of new operating framework (announced by $\mathrm{RBI}$ in May 2011) on long term interest rate movements indicated that the communication initiatives, as a strategic tool, have only a limited causal relationship between the variables. This is in contrast to the overnight interest rate movement, which is found to be closely synchronised with the policy rate, since the announcement of new operating framework by RBI. It may therefore be concluded that larger macro-economic fundamentals, rather than communication initiatives, may take lead in influencing market expectations about the behavior of long-term rates.

\section{Contents of structured communication differ across the policy options thrown up by Impossible Trinity}

Considerations of Impossible Trinity resulted in differences in components of structured communication from $\mathrm{RBI}$ to market participants concerning its actions around the two policy options. The monetary policy related communication regarding the past and the present state of economy has been largely structured with periodic information consistently placed in the public domain. Similar is the experience with regard to periodic information on foreign exchange pertaining to the previous periods (relating to foreign exchange turnover, manner of utilisation of foreign exchange reserves, assessment of their adequacy etc).

However, understandably, while in the context of monetary policy communication attempt has been made by RBI to stipulate a single policy target and provide "guidance" on future policy actions, with explanation of risks, the obvious Impossible Trinity condition limited its ability to target a particular exchange rate level nor has given it adequate flexibility to openly state in the public domain about the timing of its intervention in the forex market.

\footnotetext{
${ }^{7}$ Remarks made in an interview in The Wall Street Journal, conducted by Alex Frangos and originally published on WSJ online on February 13, 2012.
} 


\section{Unpredictability is an intentional outcome in regard to policy option that is not pursued by the RBI}

The differentiated approach, therefore, resulted in "predictability of action" to a large extent in regard to communicated stance of conduct of monetary policy and "uncertainty of action" in regard to non-interventionist policy stance of managing exchange rate volatility. While markets are able to signal the policy stances through the clues provided by $\mathrm{RBI}$ in its guidance, the ambiguity in the monetary policy statements of $\mathrm{RBI}$ that "it will intervene in the market at an appropriate time, when the circumstances make it necessary" led to uncertainty in the market participants as to when RBI will intervene in the market and what circumstances will really prompt it to do so. This aspect has been explained as a communication strategy by RBI Governor Dr Duvvuri Subbarao when he stated in this context as follows: "A central bank should have two policies, one strategic policy that is clearly laid out and stable, and another tactical policy that is more unpredictable. On tactical policy, it pays to be a bit unpredictable on how you intervene in forex market ${ }^{\prime 8}$. The unpredictable nature of the action also enabled $\mathrm{RBI}$ to warn the corporates about their forex open positions by making them fully aware that the exchange rates are market determined and they are not advised to look upon to RBI when there is significant volatility in the market. This sort of messaging helps corporates to be mindful of risks that may arise from the forex open positions, if any, they would intend to pursue in the foreign exchange market.

\section{Ambiguity can be reduced, if not eliminated, through other communication} tools

$\mathrm{RBI}$, however, ensured that this uncertainty or ambiguity in communication of its stated policy stance is not impacting its credibility. It has been vocal through other instruments and measures such as frequent media interactions and speeches wherein the rationale of its non-interventionist stance is justified to the market participants with appropriate rationale. This has been supported with data placed in the public domain (in the context of forex related data, in the format required under SDDS) the assessment of adequacy of forex reserves and the need to use them sparingly in the extreme volatile conditions.

\section{Banking Regulation - Can it substitute the need for Central Bank communication?}

Finally, the experience of $\mathrm{RBI}$ in the recent period raises one pertinent but not so far researched question either in the developed economy or EME context - whether timely regulation can substitute effective communication by the Central bank? The position of RBI as the Central Bank on one hand and the Banking supervisor on the other hand leads to this interesting question. Because, after a review of the recent experience, it can be observed that the $\mathrm{RBI}$ resorted to eliminate the ambiguity of its policy stance on exchange rate policy (created in its capacity as a central bank), by restoring its credibility through a host of regulatory measures (announced in its capacity as a banking supervisor), to supplement its efforts to reduce volatility. These timely regulatory actions have enabled to curb the speculative activity in the forex market and enabled RBI to meet its objective of smoothening the exchange rate.

\footnotetext{
8 "Pays to be Unpredictable" February 2, 2012: News article accessed online on March 30, 2012 at <businessworld.in>
} 
In this context it is apt to quote, Joseph Stiglitz, who observed that India's policymakers, "particularly the RBI, are already doing a great job. I wish the U.S. Federal Reserve displayed the same understanding of the role of regulation that the $R B I$ has done, at least so far" ${ }^{\prime \prime}$ While the context he had used is the development of regulation in relation to the prevention of building up asset bubbles, the same can be aptly used to describe the role of regulation in designing an effective communication strategy by RBI.

It can therefore be concluded that the Impossible Trinity of International Economics not only has a policy dimension but also impacts the communication strategy of the central banks in EMEs. It offers middle ground solutions by reducing the policy options to the "dilemma" of choosing between monetary policy independence and exchange rate stability. While the research in regard to central bank largely focuses on the former aspect (monetary policy independence), the experience of $\mathrm{RBI}$ proves the fact the impossible trinity, in its modified form, did introduce differentiated communication strategies by RBI with regard to these policy options, supplementing the same with nontraditional communication tools. The role of regulation, in the context of central bank communication, especially when the central bank is also a banking supervisor, is also another interesting research question on which further empirical studies can be focused upon.

9 "India well placed to take a Round 2 of Recession" May 29, 2010: News article accessed online March 30, 2012 at $<$ timesofindia.indiatimes.com> 


\section{Extracts of "Guidance" given by RBI during Monetary Policy Announcements of FY 2011-12}

\section{Annual Policy announcement (dated May 3, 2011)}

The Bank's baseline inflation projections are that the inflation rate will remain close to the March 2011 level over the first half of 2011-12, before declining. These projections factor in an upward revision of petrol and diesel prices. While the persistence of inflation over the next few months has been incorporated in this policy, the Reserve Bank will continue to persevere with its anti-inflationary stance.

\section{First quarter review of Monetary Policy (dated July 26, 2011)}

Going forward, the monetary policy stance will depend on the evolving inflation trajectory, which, in turn, will be determined by trends in domestic growth and global commodity prices. A change in stance will be motivated by signs of a sustainable downturn in inflation.

\section{Second quarter review of Monetary Policy (dated October 28, 2011)}

The projected inflation trajectory indicates that the inflation rate will begin falling in December 2011 (January 2012 release) and then continue down a steady path to 7 per cent by March 2012. It is expected to moderate further in the first half of 2012-13. This reflects a combination of commodity price movements and the cumulative impact of monetary tightening. Further, moderating inflation rates are likely to impact expectations favourably. These expected outcomes provide some room for monetary policy to address growth risks in the short run. With this in mind, notwithstanding current rates of inflation persisting till November (December release), the likelihood of a rate action in the December mid-quarter review is relatively low. Beyond that, if the inflation trajectory conforms to projections, further rate hikes may not be warranted. However, as always, actions will depend on evolving macroeconomic conditions.

It must be emphasised, however, that several factors - structural imbalances in agriculture, infrastructure capacity bottlenecks, distorted administered prices of several key commodities and the pace of fiscal consolidation - combine to keep medium term inflation risks in the economy high. These risks can only be mitigated by concerted policy actions on several fronts. In the absence of progress on these, over the medium term, the monetary policy stance will have to take into account the risks of inflation surging in response to even a moderate growth recovery.

\section{Third quarter review of Monetary Policy (January 24, 2012)}

In reducing the CRR, the Reserve Bank has attempted to address the structural pressures on liquidity in a way that is not inconsistent with the prevailing monetary stance. In the two previous guidances, it was indicated that the cycle of rate increases had peaked and further actions were likely to reverse the cycle. Based on the current inflation trajectory, including consideration of suppressed inflation, it is premature to begin reducing the policy rate. The reduction in the policy rate will be 
conditioned by signs of sustainable moderation in inflation. However, the persistence of tight liquidity conditions could disrupt credit flow and further exacerbate growth risks. In this context, the CRR is the most effective instrument for permanent liquidity injections over a sustained period of time. The reduction can also be viewed as a reinforcement of the guidance that future rate actions will be towards lowering them.

However, it must be emphasised that the timing and magnitude of future rate actions is contingent on a number of factors. Policy and administrative actions, which induce investment that will help alleviate supply constraints in food and infrastructure, are critical. Initiatives to narrow skill mismatches in labour markets will help ease the pressure on wages. The anticipated fiscal slippage, which is caused largely by high levels of consumption spending by the government, poses a significant threat to both inflation management and, more broadly, to macroeconomic stability.

Strong signs of fiscal consolidation, which will shift the balance of aggregate demand from public to private and from consumption to capital formation, are critical to create the space for lowering the policy rate without the imminent risk of resurgent inflation. In the absence of credible fiscal consolidation, the Reserve Bank will be constrained from lowering the policy rate in response to decelerating private consumption and investment spending. The forthcoming Union Budget must exploit the opportunity to begin this process in a credible and sustainable way. 


\section{Bibliography}

1. Aizenman (2010) "The Impossible Trinity (aka The Policy Trilemma)" in the Encyclopedia of Financial Globalisation (May).

2. Aizenman J M, Chinn and $\mathrm{H}$ Ito (2008). "Assessing the Emerging Global Financial Architecture: Measuring the Trilemma's Configurations over Time" NBER Working Paper No. 14533.

3. Andersson, M., H. Dillén and P. Sellin (2001) "Monetary policy signaling and movements in the Swedish term structure of interest rates" Sveriges Riksbank Working Paper Series 132.

4. Blinder, Alan S (2004) "The Quiet Revolution: Central Banking Goes Modern" New Haven, CN: Yale University Press.

5. Blinder, Alan S (2009) "Talking about monetary policy: the virtues (and vices?) of central bank communication" Basel: Bank for International Settlements (BIS) Working Papers No 274.

6. Blinder, AS, M Ehrmann, M Fratscher, J de Haan \& D-J Hansen (2008) "Central bank communication and monetary policy: a survey of the evidence" Journal of Economic Literature, 46(4), pp 910-45.

7. Cook, T. and Hahn, T (1989). "The effect of changes in the federal funds rate target on market interest rates in the 1970s" Journal of Monetary Economics 24 (3): pp 331-351.

8. Das, Rituparna (2011). "Indian G-Sec Market: How the Term Structure Reacts to Monetary Policy": Handbook of Fixed Income Securities Volume II, Verlag, 2011.

9. Ehrmann, Michael, and Marcel Fratzscher. 2007b. "Communication by Central Bank Committee Members: Different Strategies, Same Effectiveness?" Journal of Money, Credit, and Banking, 39(2-3): 509-41.

10. Faust, J., Swanson, E. and Jonathan, H. W. (2002). "Identifying VARS Based On High Frequency Futures Data". Board of Governors of the Federal Reserve System. International Finance Discussion Paper No 720.

11. Guthrie G and J Wright (2000). "Open Mouth Operations" Journal of Monetary Economics 46, 489-516.

12. Hutchison, Michael; Sengupta, Rajeswari and Singh, Nirvikar (2010) "India's trilemma: Financial liberalization, exchange rates and monetary policy" Munich Personal RePEc Archive (MPRA) Paper No. 25327 (September).

13. Kobayashi, Koji (2009) "The Trilemma of the International Financial System in India" Mizuho Research Institute (September).

14. Kohli, R. (2001). "Real Exchange Rate Stabilisation and Managed Floating: Exchange Rate Policy in India," 1993-99, ICRIER Working Paper 59 (October). 
15. Kohn, Donald L and Brian Sack (2004) "Central Bank Talk: Does it Matter and Why?" Macroeconomics, Monetary Policy, and Financial Stability, Ottawa: Bank of Canada, 175-206.

16. Kuttner, K. N. (2001). "Monetary policy surprises and interest rates: evidence from the Fed funds futures market”. Journal of Monetary Economics 47(3): pp 523-544.

17. Kydland FE and Prescott EC (1977) "Rules rather than discretion: The inconsistency of optimal Plans" Journal of Political Economy. 85(3), 473-491.

18. Moessner, Richhild and Nelson, William (2008) "Central bank policy rate guidance and financial market functioning" Basel: Bank for International Settlements Working Paper No. 240.

19. Mohan, Rakesh and Kapur, Muneesh (2009) "Volatile Capital Flows and Indian Monetary Policy" Stanford Center for International Development Working Paper No. 401 (November).

20. Mohanty, Deepak (2011) "Changing Contours of Monetary Policy in India" Speech given at the Royal Monetary Authority of Bhutan, Thimpu on December 1, 2011.

21. Obstfeld M, J C Shambaugh and A M Taylor (2008). "Financial Stability, The Trilemma, and International Reserves"NBER Working Paper 14217 (August).

22. Overtveldt, Johan Van (2010) "Bernanke's Test - Ben Bernanke, Alan Greenspan, and the drama of the Central Banker" Chicago: A Gate Publishing.

23. Pattanaik, S and S Sahoo (2001): "The Effectiveness of Intervention in India: An Empirical Assessment", Reserve Bank of India Occasional Papers.

24. Ranjan, Rajiv and Dua, Pami (2010) "Exchange Rate Policy and Modelling in India" Development Research Group (DRG) Study released by RBI on February 25, 2010.

25. Reddy, YV (2008). "The Virtues and Vices of Talking About Monetary Policy: Some Comments". Speech given at the 7th BIS Annual Conference at Luzern, Switzerland on June 26, 2008.

26. Sengupta, Abhijit and Manjhi (2011) "Capital Flows and the Impossible Trinity: The Indian Experience" Discussion Papers in Economics (11-02) School of International Studies. Jawaharlal Nehru University, India.

27. Subbarao, Duvvuri (2011). "Dilemmas in Central Bank Communication Some Reflections Based on Recent Experience". Speech given at the second Business Standard Annual Lecture at New Delhi on January 7, 2011.

28. Woodford, Michael (2005). "Central bank Communication and Policy Effectiveness" Paper presented at the Federal Reserve Bank of Kansas City Symposium "The Greenspan Era: Lessons for the Future" August 25-27, 2005. Jackson Hole, Wyoming. 